\title{
AS BOLSAS DE VALORES COMO UM FENÔMENO COMERCIAL
}

\author{
Carlos Eduardo Vergueiro \\ Mestrando em Direito Comercial pela Faculdade de \\ Direito da Universidade de São Paulo
}

\begin{abstract}
Resumo:
O objetivo deste trabalho é o de apresentar as Bolsas de Valores como um Fenômeno próprio da História do Comércio/Comerciantes/Direito Comercial. Para tanto, também são analisados os conceitos e origens históricas do termo, a disciplina juridica e as finalidades atribuídas pelo Direito às Bolsas de Valores no Brasil. Por fim, há uma conceituação formulada pelo autor, como conclusão do trabalho.
\end{abstract}

\begin{abstract}
:
This article has been written for the purpose of describing Stock Exchanges as a phenomenon related to Business History/Business Men/Business Law. As steps taken to reach such goal, it will be examined the concepts and historical origins of the expression Stock Exchange, legal discipline and the purposes that Law grant to Stock Exchanges in Brazil. At last, but not least, the author shows his own concept of Stock Exchanges as a conclusion for the work herein.
\end{abstract}

Unitermos: Bolsas de Valores; Mercado de Capitais; Valores Mobiliários

"Todo o mundo especula na Bolsa. Os aumentos de rendas que conseguimos com o trabalho certamente nos alegram, mas os lucros auferidos graças ao acaso valem uma dupla alegria." (Winston S. Churchill)'

1. Introdução

Teria Winston Churchill agido de modo correto ao apresentar as Bolsas de Valores como locais onde a especulação seria a atividade preponderante? Certamente, a resposta à indagação seria negativa se fossem consideradas certas outras características presentes nas atividades desempenhadas pelas Bolsas de Valores, especialmente aquelas

1. In R. I. Warshow, The Story of Wall Street, 1929, trad. port. de C. Fonseca, Wall Street: História da Bolsa de Nova York desde suas origens até 1930, São Paulo, Cultura Brasilcira, 193?, p. 8. 
lembrados por J. X. Carvalho de Mendonça, que afirmou que as bolsas têm a capacidade de impulsionar e facilitar, com garantias de sinceridade, as atividades empresariais. Isso ocorre, no seu entendimento, a partir da concentração da oferta e da procura, o que vem a facilitar o concurso dos capitalistas para o sucesso dos novos empreendimentos empresariais. ${ }^{2}$

Questões como essa, que analisa a relevância das Bolsas para a economia nacional, têm permeado o imaginário e o debate sobre o tema das Bolsas de Valores há muito tempo. Bulgarelli, nesse sentido, lembra que a expressão "Bolsa de Valores" constitui verdadeira palavra mágica, que atrai a atenção das pessoas, trazendo à mente a existência de negócios em grande escala e de valor altissimo. ${ }^{34}$

Muito mais do que simplesmente analisar a relação de importância que se estabelece entre as Bolsas de Valores e a Economia, este artigo tem por finalidade apresentar as Bolsas de Valores como um Fenômeno próprio do Comércio/ Comerciantes/Direito Comercial, o que somente pode acontecer se, inicialmente, forem lembradas as conceituações tradicionalmente aplicadas à expressão "Bolsa", aproveitando para também mencionar a disciplina jurídica do tema, quando se irá procurar entender como o Direito nacional classifica as Bolsas de Valores ${ }^{5}$ e o que delas espera. Para esse item, a verificação da disciplina introduzida pela Lei 6.385/76, com a verificação de existência, ou não, de prestação de serviço público, e seu regramento jurídico, torna-se imprescindivel, como se passa a analisar a partir de agora.

3. Cf. Bolsas de Valores in Enciclopédia Saraiva de Direito, v.12, (1977).

4. Em outra ocasião, BULGARELLI chcgou a afirmar que scria inútil enfatizar a importância das Bolsas, hoje, no mundo moderno, cf. Curso de Direito Comercial, 14 cd., São Paulo, Atlas, 1999, p. 226.

5. Todo o cstudo aqui registrado procura cvidenciar aspectos gerais aplicávcis a quaisquer Bolsas de Valores operantes no Brasil. Entretanto, ć válido lembrar que existe apenas uma Bolsa de Valores que negocia com títulos privados (a BOVESPA - Bolsa de Valores de São Paulo) c outra que também negocia, com cxclusividade, titulos públicos (no caso, a BVRJ - Bolsa de Valorcs do Rio de Janciro). Existem outras setc Bolsas de Valores no pais, as quais se denominam: (1) Bolsa de Valores de Minas, Espírito Santo c Brasilia - BOVMESB; (2) Bolsa de Valores do Extremo Sul - BVES; (3) Bolsa de Valores do Paraná - BVPR; (4) Bolsa de Valores da Bahia, Scrgipe c Alagoas - BVBA; (5) Bolsa de Valores de Pemambuco c Parába - BVPP; (6) Bolsa de Valores Regional - BVRG, representando Ceará c Rio Grande do Nortc; c, (7) Bolsa de Valores de Santos - BVST. O que importa notar é que, no final do ano de 1999, todas cssas nove Bolsas de Valorcs protagonizaram um processo de integração, que resultou na concentração das atividades de negociação de valores mobiliários na BOVESPA $\mathrm{c}$ na BVRJ. As demais Bolsas de Valores não mantêm mercado para a negociação de valores mobiliários. Sobre o tema, recomendamos a lcitura do nosso artigo A Integração das Bolsas Nacionais e o Aumento de Competitividade, publicado na Revista da Faculdade de Dircito da Universidade de São Paulo, vol. 96, cdição de 2001, pp. 671-683, c que foi vencedor do II Concurso de Monografias da Comissão de Valores Mobiliários. 


\section{Conceituações Tradicionais da Palavra "Bolsa"}

A compreensão das formas pelas quais a expressão Bolsa foi tradicionalmente conceituada é uma tarefa que se mostra oportuna para o estudo que se pretende realizar neste artigo. ${ }^{6}$

$\mathrm{Na}$ verdade, sempre existiram quatro significados para a palavra Bolsa, representando histórias particularmente interessantes sobre os hábitos do comércio, e que trazem à mente a idéia da Bolsa como sendo: (1) a reunião de interessados em fazer negócios, (2) o local de reuniões dessa natureza, (3) o conjunto dos negócios realizados, ou (4) a própria instituição Bolsa de Valores, como será melhor explicado a seguir.

Os Comercialistas afirmam que a origem da palavra "Bolsa", significando uma reunião de pessoas com o propósito de realizar negócios, ou mais precisamente o local onde essas reuniões eram realizadas, provém da cidade flamenga de Bruges, ainda no século XIII. A esse respeito, Oscar Barreto Filho explicou que, nessa ocasião, uma familia nobre, de nome Van der Bürse, assinalava o frontispicio de sua casa com escudos de armas, em que figuravam três bolsas - por extensão, tal nome passou a designar uma praça contigua à casa, a qual constituía o centro de reunião dos mercadores. ${ }^{7}$ Dirigir-se à Bolsa, nessa acepção, queria significar ir a um local determinado, onde já se sabia que estariam pessoas interessadas em realizar negócios.

A própria Bolsa de Nova York também apresenta uma história semelhante. Em 17 de maio de 1792, 24 corretores resolveram assinar um contrato que formaria o primeiro Mercado de Valores Mobiliários de Nova York. E as suas reuniões eram feitas embaixo de uma árvore na Wall Street.

O Código Comercial de 1850 fez uso desses significados de local/ reunião para designar as Bolsas, por ele abrangidas implicitamente no conceito de Praças do Comércio, da seguinte maneira: "Art. 32. Praça do comércio é não só o local, mas também a reunião dos comerciantes, capitães e mestres dos navios, corretores e mais pessoas empregadas no comércio."

Atualmente, as Bolsas de Valores tem organizado ambientes virtuais para a negociação de valores mobiliários. Esses ambientes mantêm as mesmas particularidades presentes nos tradicionais pregões das Bolsas de Valores porque neles

6. As conccituações históricas da palavra "Bolsa" podem ser utilizadas tanto para o entendimento das Bolsas de Valores, que constitucm o objeto de cstudo neste trabalho, como para a comprecnsão do funcionamento das Bolsas de Mcreadorias, que não cstão dirctamente tratadas neste trabalho. Diferença básica entre as duas cntidades ć o bem objeto de negociação cm cada uma.

7. Cf. Natureza Juridica das Bólsas de Valores, no Direito Brasileiro, in RT 283/7. 


\section{As Bolsas de Valores como um Fenômeno Comercial}

Feita a descrição do capítulo anterior, trata-se agora de inovar para apresentar as "Bolsas de Valores" como sendo um fenômeno próprio do Comércio/ Comerciantes/Direito Comercial; o que se justifica pelo fato delas estarem diretamente relacionadas com as Sociedades Anônimas e, também, com as vontades que estiveram presentes na mente dos comerciantes desde o desenvolvimento das sociedades comerciais e das próprias Bolsas de Valores. O acesso ao "capital barato" também se insere nessa perspectiva.

Certamente, as Bolsas de Valores e as Sociedades Anônimas formaram uma dupla que têm promovido benefícios mutuamente através dos tempos. As Sociedades Anônimas, que representam um dos casos de maior êxito dentre as criações do Direito Comercial, encontraram nas Bolsas uma fonte de tomada de capitais que lhes permitiram obter o substrato financeiro necessário para suas atividades.

Em que lugar poderiam as ações melhor livremente circular do que não numa Bolsa de Valores? Não são as Bolsas os espaços onde quaisquer critérios (como raça, origem do capital, religião ou até a reputação) que eventualmente poderiam afastar vendedores dos compradores, e vice-versa, podem também ser melhor afastados? Interessados em investir em ações de determinadas empresas se dirigem para as Bolsas com o propósito de adquirir essas ações de quem quer as detenha, da mesma forma que vendedores alienam suas ações para quem lhes pagar o preço que desejam.

E, se lembrarmos que a negociação em Bolsa de Valores no Brasil pressupõe a presença de um corretor, o que afasta a possibilidade de negociação direta entre as partes, como admitir que preconceitos particulares possam estar presentes numa compra e venda de ações feita em Bolsa? A função econômica das Bolsas tem como objetivo facilitar o ingresso de capitais para as Sociedades Anônimas, valendose, principalmente, da concentração da oferta e da demanda por valores mobiliários.

Olhando esse mesmo cenário sob a ótica das próprias Bolsas de Valores, também se pode dizer que as Sociedades Anônimas lhes têm trazido benefícios; o que não se deve apenas à sua qualidade de emissoras de valores mobiliários. A questão é que, na exata medida em que as Sociedades Anônimas (abertas) trazem em sua natureza um apelo ao público em geral para que adquira suas ações, acaba sendo gerado um contingente enorme de pessoas (fisicas ou jurídicas) que, por motivos pessoais, desejam encontrar um local (ou uma instituição!) na qual possam rapidamente alienar ou aumentar suas participações societárias, se assim o desejarem. 
as Bolsas exercerão o seu poder para: controlar o acesso das pessoas que estarão operando com valores mobiliários, fiscalizar essas operações, cobrar contraprestação pecuniária pelos serviços prestados, recolher informações sobre as operações e repassálas a quem interessar.

Mas esses não são os únicos significados atribuídos à palavra Bolsa, que também pode significar o conjunto de negócios nela realizados. Frases do tipo "A Bolsa despencou!", “A Bolsa subiu hoje” "Todos estão felizes com a alta da Bolsa" ilustram como a palavra Bolsa pode ser utilizada como sinônimo dos negócios nela realizados. Nesse aspecto é que está inserida uma das principais funções das Bolsas, qual seja a de produzir informações sobre empresas, setores empresarias (siderurgia, telecomunicações etc), o que se reflete diretamente sobre as expectativas da Economia de um País.

É interessante notar que essa característica também estava presente no Código Comercial do Império, cujo art. 33 determinava "O resultado das negociações que se operarem na praça determinará o curso do câmbio, e o preço corrente das mercadorias, seguros, fretes, transportes de terra e água, fundos públicos, nacionais ou estrangeiros, e de outros quaisquer papéis de crédito, cujo curso possa ser anotado."

Sendo as Bolsas pessoas jurídicas de Direito Privado, e desempenhando as mesmas funções auxiliares para a Comissão de Valores Mobiliários, conforme será explicado abaixo, não se pode esquecer de atribuir à expressão "Bolsa" aspectos institucionais. Dizer que a "Bolsa suspendeu as negociações com ações da companhia X" ou ainda "A Bolsa comprou um novo prédio para suas instalações" exemplificam essa característica, que realça a qualidade de sujeito de direitos e deveres presentes nas Bolsas.

Os quatro significados que tradicionalmente foram dados à "Bolsa" têm permanecido complementares com o passar do tempo, o que permite que atualmente se diga que a Bolsa representa:

(1) a reunião de interessados em fazer negócios, que não é uma simples reunião, mas sim uma agremiação especial em função dos temas (compra e venda de valores mobiliários) que são nela tratados,

(2) o local de reuniões dessa natureza, seja esse local um espaço físico o pregão ou um ambiente virtual especialmente criado para tanto, e regulado pela própria Bolsa,

(3) o conjunto dos negócios realizados no pregão ou no espaço virtual, ou

(4) a própria instituição Bolsa de Valores, como sujeito de direitos e deveres, deveres esses que são reforçados pela Lei n. 6.385/76, como será tratado abaixo, logo após da apresentação das Bolsas de Valores como um fenômeno comercial. 
Desse desejo que está no interior de cada acionista, é possível compreender como é importante a existência de uma Bolsa de Valores, que acaba influenciando (na mente do interessado) a vontade de adquirir ações, pois sabe que poderá rapidamente delas se desfazer em mercado de Bolsa.

A relação de sucesso dessa cooperação que as Bolsas de Valores e as Sociedades Anônimas protagonizaram durante o tempo pode ser vista desde a "famosa avó das Sociedades Anônimas de agora”, a Companhia das Índias Ocidentais, cujo desenvolvimento foi proporcionado, em grande parte, conforme lição de Waldemar Ferreira, pela existência da Bolsa de Amsterdã, ainda no século XVII, "onde os titulos poderiam ser facilmente transferidos $" 8$

Um terceiro grande critério que justifica a relação de parceria entre as Bolsas de Valores e as Sociedades Anônimas é o fato das Bolsas permitirem que as Sociedades possam contar com "capital barato" para darem continuidade a suas atividades.

Quando uma empresa (no caso, uma Sociedade Anônima) verifica que precisa de mais recursos do que dispõe para realizar um negócio que lhe seja interessante (por exemplo, a compra de uma outra empresa, a montagem de nova fábrica, a criação de filiais ou subsidiárias, etc), seus administradores sabem que poderão optar por dois caminhos: o primeiro é a contratação de empréstimos com juros que, pelo seu elevado valor, podem desestimular todo o negócio pretendido; o segundo é o aumento do capital social em valor que permita a entrada de recursos no caixa em montante suficiente para a realização do negócio. E onde podem ser encontrados interessados em participar desse aumento, dando dinheiro em troca de ações? Nenhum lugar melhor do que numa Bolsa de Valores.

As formas de remuneração dos acionistas, especialmente os dividendos e os juros sobre o capital próprio, tendem a ser mais baratos para a empresa do que o pagamento do juros e do principal que seriam devido no caso da contratação de empréstimo. Por isso, aumentos de capital que procuram atrair a atenção do público investidor são procurados pelas empresas como forma de obtenção de "capital barato" ou ao menos, de "capital mais barato"

Por impulsionar as Sociedades Anônimas, e por conseqüência a economia de um país, as Bolsas de Valores podem ser caracterizadas como um fenômeno próprio do comércio, que nelas acredita e por elas capta os recursos necessários para a consecução de suas atividades. Por óbvio, não se está, aqui, a esquecer da transformação

8. Cf. Tratado de Direito Comercial, $4^{\circ}$ v., São Paulo, Saraiva, 1961, p. 17. 
dos paradigmas do Direito Comercial, que agora tèm como objeto de estudo a empresa (ou as atividades de empresa) e não a figura do comerciante. Mas como todo o desenvolvimento do tema das Bolsas de Valores se deu ainda na época dos comerciantes, valendo recordar que eram os próprios homens do comércio que se dirigiam à praça de Bruges no século XIII, não havia outra forma de comentar o tema.

4. Disciplina Juridica das Bolsas de Valores no Brasil e Análise da Existência de Prestação de Serviço Público

As questões da disciplina jurídica das Bolsas de Valores no Brasil e da análise da existência de prestação de serviço público constituem o ponto central da classificação das Bolsas de Valores perante o Direito. ${ }^{9} \mathrm{O}$ ponto de partida, nesse contexto de investigação, é o exame das disposições que o Direito brasileiro, através da Lei n. $6.385 / 76$, prevê para as Bolsas de Valores, principiando pelos deveres e, na seqüência, comentando outros aspectos da disciplina legal.

\subsection{Constituição e Funcionamento}

Em primeiro lugar, a criação e o funcionamento das Bolsas de Valores no Brasil não é um sistema de total liberdade privada. Ao contrário, o Direito brasileiro em muito influencia, deixando reduzida margem de liberdade. A competência para definir as condições de constituição das Bolsas, bem como sua forma jurídica, seus órgãos sociais e respectivas formas de preenchimento foi atribuída à CVM pelo art. 18 da Lei n. 6.385/76. Portanto, não é possível que pessoas interessadas simplesmente resolvam organizar uma Bolsa de Valores e iniciar suas operações a seu prazer.

Da mesma forma, a Comissão tem a prerrogativa legal de editar normas sobre: (1) o exercício do poder disciplinar pelas Bolsas, (2) o número de memuros da Bolsa, (3) requisitos mínimos para a eleição dos administradores da Bolsa, (4) administração da Bolsa, (5) espécies de operações autorizadas, (6) responsabilidades dos intermediários, (7) emolumentos e comissões cobrados pelas Bolsas, (8) condições de realização das operações a termo e (9) métodos e práticas de observância obrigatória em bolsa. (art. 18, inciso I, alíneas c, d, e, f e inciso II, alínea a).

9. Para uma análisc histórica do enquadramento lcgal das Bolsas de Valores perante o Dircito brasilciro, recomendamos, alćm do artigo de Oscar Barreto Filho c do Tratado de J. X. Carvalho de Mendonça, mencionados nas notas 7 c 2 supra, a leitura do Tratado de Direito Comerclal de Waldemar Ferreira, precisamente o $11^{\circ}$ volume, no itcm $\$ 576$ (demais dados bibliográfico, vide nota 8 ). 
No que diz respeito à constituição e funcionamento das Bolsas, a Resolução 2.690/00 do Conselho Monetário Nacional, que foi o ente competente no lugar da CVM até a entrada em vigor da Medida Provisória n. 8/2001 ${ }^{10}$, estabelece um regramento também permeado de influência sobre a vontade dos membros e fundadores das Bolsas de Valores."

De acordo com o art. $1^{\circ}$ do Regulamento anexo à Resolução n. 2.690/00, as Bolsas de Valores deverão ser constituídas como associações civis ${ }^{12}$ ou como sociedades anônimas. A Bovespa, que é a única Bolsa de Valores operante com valores mobiliários privados na atualidade foi constituída como associação civil sem finalídade lucrativa.

O que chama a atenção desse dispositivo é que, ao contrário do regime anterior, passou-se a prever que as Bolsas poderiam ser constituídas como sociedades anônimas, o que dá abertura para que a própria Bolsa coloque suas próprias ações em negociação. Colocar parcelas do próprio capital em circulação é uma medida que, para muitos, pode auxiliar no fortalecimento institucional da própria Bolsa de Valores. O exemplo vem da Europa: em 22 de setembro de 2000, foi oficializada a criação da Euronext, que é o resultado da fusão entre as Bolsas de Valores de Amsterdam (Amsterdam Exchanges), Bruxelas (Brussels Exchanges) e Paris (Paris Bourse). A própria Euronext chegou a anunciar sua intenção de colocar suas próprias ações para negociação.

Porém, a famosa e grande Bolsa de Valores de Nova Iorque, a New York Stock Exchange, permanece como sendo uma associação sem fins lucrativos. Entretanto, por força do mesmo Regulamento, a colocação de ações em negociação dependerá de autorização da CVM.

No que diz respeito ao funcionamento das Bolsas de Valores, a vontade da própria Bolsa em se autodisciplinar também segue diretrizes estatais. A Resolução n. 2.690/00 estabelece quais atividades são objeto das Bolsas de Valores, que o estatuto social e regimento interno deverão ter alterações aprovadas pela CVM, conteúdo mínimo do estatuto social, formação do patrimônio social, datas de início e término do exercício social, demonstrações financeiras, composição dos órgãos de administração, disciplina legal dos membros das Bolsas, etc.

10. A MP 8/01 foi convertida na Lci n. 10.411/02, c suas disposiçõcs altcram a própria Lci n. 6.395/76.

11. É intercssante notar que o Dircito brasilciro já vem há tempos accitando a idćia de recepção, a qual podemos invocar para accitar a vigência da referida resolução nos dias de hojc. O exemplo da recepção do Código Tributário Nacional pela Constituição de 1988 talvez scja o cxcmplo de maior relcvância prática sobre o tema da recepção.

12. Por óbvio, a Resolução n. 2.690/00 usa a expressão "associação civil" no lugar de "associação" porque foi promulgada antes da vigência do Novo Código Civil, que altcrou cssas cxpressõcs. 
A influência estatal é evidente.

\section{Supervisão pela CVM e Deveres Legais}

Reforçando a idéia de influência legal sobre as atividades das Bolsas de Valores, $o$ art. 17 da Lei n. 6.385/76 apresenta duas idéias antagônicas (ou uma reduzindo as disposições da outra...). Afirma esse artigo que as Bolsas de Valores possuem autonomia administrativa, financeira e patrimonial, mas devem operar sempre sob a "supervisão da CVM".

Ou seja, a interferência estatal dá-se não somente na constituição e definição dos estatutos, mas também no cotidiano das atividades desempenhas pelas Bolsas de Valores. Essa influência, na verdade, deve ser vista como sendo uma medida positiva pois a existência de um órgão estatal fiscalizando as operações da Bolsa só aumenta as garantias e seguranças que os investidores desejam para participarem desse mercado.

Além da influência, o segundo aspecto que se destaca é a atribuição de deveres às Bolsas de Valores por parte da Lei n. 6.385/76. A interpretação do art. 8 (inc. $\mathrm{V}$ e $\$ 1^{\circ}$ ) leva ao entendimento de que há delegação de competência concorrente para que as Bolsas possam fiscalizar as operações realizadas em seus mercados, bem como as pessoas envolvidas e as empresas emissoras de valores mobiliários. Nesse artigo, está afirmado que compete à Comissão de Valores Mobiliários, sem exclusão da competência das Bolsas de Valores, fiscalizar e inspecionar as companhias abertas dando prioridade às que não apresentem lucro em balanço ou às que deixem de pagar o dividendo mínimo obrigatório.

A atribuição de competência para as Bolsas também é importante porque facilita e agiliza a fiscalização dos negócios, garantindo maior proteção aos investidores.

Por fim, também reforçando a idéia de vínculo entre as Bolsas e a CVM, diz o art. 14 da Lei n. 6.385/76 que a Comissão de Valores Mobiliários poderá prever, em seu orçamento, dotações de verbas às Bolsas de Valores.

Dessa forma, as Bolsas de Valores não são simples integrantes do sistema de distribuição de valores mobiliários; possuem competências e deveres em relação aos mercados por elas organizados, atuando sempre conforme a supervisão da Comissão de Valores Mobiliários.

\subsection{Exame de Existência de Prestação de Serviço Público}

Comparato, com a publicação de artigo sobre a natureza juridica das Bolsas de Valores, concluiu que elas são entidades privadas prestadoras de serviço 
público. ${ }^{13}$ No seu entendimento, a característica determinante seria a atribuição da qualidade de órgão auxiliar da CVM, com poderes e responsabilidades perante e dentro do mercado de valores mobiliários.

Concordamos com esse entendimento. As Bolsas de Valores não se situam na mesma esfera dos particulares, e essa afirmativa não está baseada somente sob a ótica da constituição e funcionamento. De forma mais forte a colocação expressa das Bolsas de Valores como órgão auxiliar da CVM (art. 17, $\$ 1^{\circ}$ ), que atuam sob a sua supervisão (art. 17, caput) e com poderes para fiscalizar operações, empresas emissoras e membros envolvidos em operações de negociação de valores mobiliários certamente as coloca em posição especial, própria daqueles que detêm poder de polícia sobre seus administrados $\left(\operatorname{art.} 8^{\circ}\right)$.

A previsão legal de destino de verbas públicas provindas da Comissão de Valores Mobiliários para as Bolsas de Valores nada mais é do que um reforço dessa idéia de prestação de serviço público por parte das Bolsas de Valores.

5. Conclusão: do Conceito Jurídico das Bolsas de Valores no Brasil

De acordo com o exposto, pode-se concluir que, em face do Direito brasileiro, pode-se atribuir às Bolsas de Valores o seguinte conceito:

São Bolsas de Valores no Brasil as entidades privadas (1) que, detentoras de direitos e deveres (2), atuam sob a supervisão e autorização da Comissão de Valores Mobiliários (3), facilitando o encontro de pessoas interessadas em comprar ou vender valores mobiliários, a partir da manutenção de mercados para tanto (4), nos quais coexiste o poder de fiscalização das próprias Bolsas de Valores com a Comissão de Valores Mobiliários. (5)

É válido conferir as causas que levaram à essa conceituação:

(1) as Bolsas de Valores são entidades privadas porque, por força da Resolução 2.690/00 do Conselho Monetário Nacional, devem se constituir sob a forma de associações ou sociedades anônimas;

(2) as Bolsas de Valores são sujeitos de direito que gozam de autonomia administrativa, patrimonial e financeira (art. 17 da Lei n. 6.385/76), mas que possuem responsabilidades em função dos mercados de negociação de valores mobiliários por

13. Cf. Natureza Juridica das Bolsas de Valores e Delimitação do seu Objeto, in Revista de Dircito Mcrcantil, Industrial, Econômico c Financciro, vol. 60, Editora Revista dos Tribunais, out/dez 1985, p. 47. 
elas mantidos (art. $17, \S 1^{\circ} \mathrm{e}$ art. $8^{\circ}$, inc. $\mathrm{V} \mathrm{c} / \mathrm{c} \$ 1^{\circ}$ ), em adição às responsabilidades inerentes a qualquer pessoa jurídica de direito privado no Brasil;

(3) nenhuma Bolsa de Valores poderá ser constituída ou exercer atividades sem autorização da CVM e cumprindo suas determinações;

(4) a facilitação do encontro de interessados em comprar ou vender valores mobiliários decorre das características das Bolsas de Valores serem locais onde se dá a reunião desses interessados, estando presentes, aqui, as definições históricas da expressão "Bolsa de Valores" Por "locais" devem ser entendidos tanto os pregões quanto os ambientes virtuais de negociação; $e$

(5) tanto as Bolsas de Valores quanto a própria CVM devem fiscalizar as operações realizadas nos mercados mantidos pelas Bolsas, em função do art. $8^{\circ}, \mathrm{V}$ e $\S 1^{\circ}$ da n. Lei $\left.6.385 / 76\right)$.

O tratamento dado pelo Direito brasileiro para o tema das Bolsas de Valores traz especificidade para as concepções históricas das Bolsas, que são os verdadeiros mercados dos valores mobiliários.

São Paulo, setembro de 2003. 
Bibliografia

BARRETO FILHO, Oscar, Natureza Juridica das Bôlsas de Valores, no Direito Brasileiro, in RT $283 / 7$.

BULGARELLI, Waldirio, Bolsas de Valores in Enciclopédia Saraiva de Direito, vol.12, (1977).

Curso de Direito Comercial, 14ª ed., São Paulo, Atlas, 1999.

COMPARATO, Fabio Konder, Natureza Juridica das Bolsas de Valores e Delimitação do seu Objeto, in Revista de Direito Mercantil, Industrial, Econômico e Financeiro, vol. 60, out/dez 1985, pp. 45-53.

FERRAZ Jr., Tercio Sampaio, e MAGLIANO FILHO, Raymundo, A Bolsa de Valores como Sistema de Poder, in Revista de Direito Econômico, maio/agosto 1980 , pp. 7-20.

FERREIRA, Waldemar, Tratado de Direito Comercial, $4^{\circ}$ vol., São Paulo, Saraiva, 1961.

GUERREIRO, José Alexandre Tavares, Bolsa de Valores, in Revista do Instituto dos Advogados do Paraná, n. 29, 2000, pp. 200-216.

LUCCA, Newton De, As Bolsas de Valores e os Valores Mobiliários in Revista do Tribunal Regional Federal da 3“Região, n. 35, jul/set, 1998, pp. 19-38.

MENDONÇA, José Xavier Carvalho de, Tratado de Direito Commercial Brasileiro, $3^{\text {a }}$ ed., vol. 6, Rio de Janeiro, Freitas Bastos, 1939.

RIPPERT, George e ROBLOT, René, Traité de Droit Commercial, Tomo 1, $13^{\text {a }}$ ed., Paris, Librarie de Droit et Jurisprudence, 1989.

ULRICH, Ruy Ennes, Da Bolsa e suas Operações, Coimbra, Imprensa da Universidade de Coimbra, 1906.

VERGUEIRO, Carlos Eduardo, A Integração das Bolsas Nacionais e o Aumento de Competitividade, in Revista da Faculdade de Direito da Universidade de São Paulo, vol. 96, 2001, pp. 671-683.

WARSHOW, Robert Irving, The Story of Wall Street, 1929, trad. port. de C. Fonseca, Wall Street: História da Bolsa de Nova York desde suas origens até 1930, São Paulo, Cultura Brasileira, 193 ?. 